\title{
Rehabilitation of Severely Resorbed Edentulous Mandible Using the Modified Visor Osteotomy Technique
}

\author{
Cassio Edvard SVERZUT ${ }^{1}$ \\ Alexandre Elias TRIVELLATO ${ }^{1}$ \\ Alexander Tadeu SVERZUT ${ }^{1}$ \\ Aníbal Henrique Barbosa LUNA ${ }^{2}$ \\ Thiago Iafelice dos SANTOS ${ }^{1}$ \\ Cassio de Barros PONTES ${ }^{3}$ \\ ${ }^{1}$ Department of Oral and Maxillofacial Surgery and Periodontology, Ribeirão Preto Dental School, \\ University of São Paulo, Ribeirão Preto, SP, Brazil \\ ${ }^{2}$ Department of Dental Medicine, Paraiba State University, João Pessoa, PB, Brazil \\ ${ }^{3}$ Private Practice, Ribeirão Preto, SP, Brazil
}

\begin{abstract}
The prosthetic rehabilitation of an atrophic mandible is usually unsatisfactory due to the lack of support tissues, mainly bone and keratinized mucosa for treatment with osseointegrated implants or even conventional prosthesis. The prosthetic instability leads to social and functional limitations and chronic physical trauma decreasing the patient's quality of life. A 53-year-old female patient sought care at our surgical service complaining of impairment of her masticatory function associated with the instability of the lower total prosthetic denture. The clinical and complementary exams revealed edentulism in both arches, while the mandibular arch presented severe reabsorption resulting in denture instability and chronic trauma to the oral mucosa. The proposed treatment plan consisted in the mandibular rehabilitation with osseointegrated implants and fixed Brånemark's protocol prosthesis after mandibular reconstruction applying the modified visor osteotomy technique. The proposed technique offered predictable results for reconstruction of the severely resorbed edentulous mandible and posterior rehabilitation with osseointegrated implants.
\end{abstract}

Key Words: alveolar ridge augmentation, dental implants, mouth rehabilitation.

\section{INTRODUCTION}

Patients wearing complete dentures for long periods usually exhibit a lack of bone and keratinized mucosa in the bearing area due to bone atrophy. Following the extraction of normally erupted teeth, the bone of the residual alveolar ridge also loses functional stimulus resulting in a progressive, accumulative and irreversible bone resorption process. Therefore the patients suffering from this phenomenon usually have unstable and non-retentive total prosthetic dentures, which results in constant trauma to the mucosa, pain, functional limitations (e.g. mastication and speech) and esthetic facial worsening (1). These problems frequently lead to social limitations and psychological impairment decreasing the patient's quality of life $(2,3)$.

The number of patients presenting severely reabsorbed edentulous mandible and searching for implant-based dental rehabilitation has increased in the last 2 decades. Many surgical techniques involving hard and soft tissue handling are proposed in the scientific indexed literature in order to maximize the prosthetic procedures (4).

Some authors have proposed a fixed or removable prosthesis supported by short dental implants (length up to $7.0 \mathrm{~mm}$ ) to rehabilitate severely reabsorbed edentulous mandibles $(1,5,6)$. Nevertheless, in cases where the patient exhibits small mandibular bone mass volume, 
there is a risk of fracture during the surgical procedure or in the immediate postoperative period $(2,3,7)$. Furthermore, in this type of treatment the ratio of implant to crown is esthetically and functionally unfavorable and the mandibular bone structure is not reinforced.

One important alternative in these cases is preprosthetic reconstructive surgery using autogenous bone graft previous to the placement of osseointegrated dental implants. Some surgical techniques have been proposed aiming both to aid the prosthetic rehabilitation and to increase the mandible bone mass $(8,9)$. However, some complications are associated with these procedures, such as: exposition and/or severe resorption of the bone graft, fractures, fistulas and sensorial deficit $(4,8,10,11)$.

This article describes a case of severely resorbed edentulous mandible in which the modified visor osteotomy technique and autogenous bone graft harvested

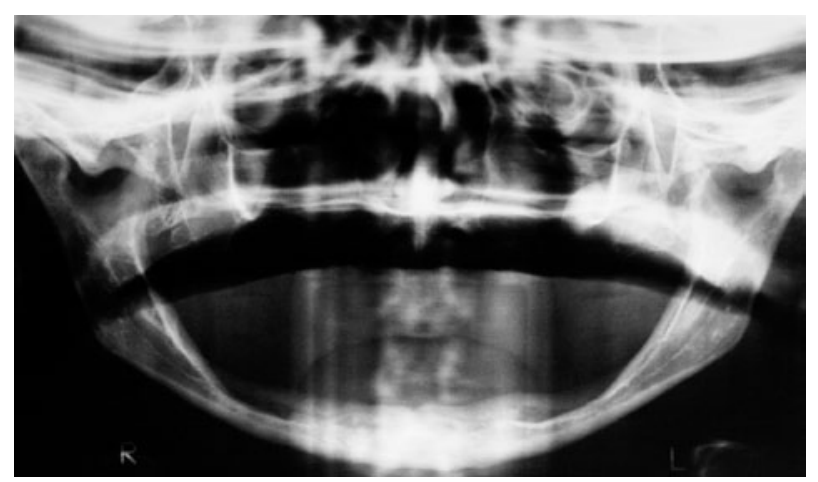

Figure 1. Panoramic radiograph exhibiting a class VI Cawood and Howell (18) mandibular resorption.

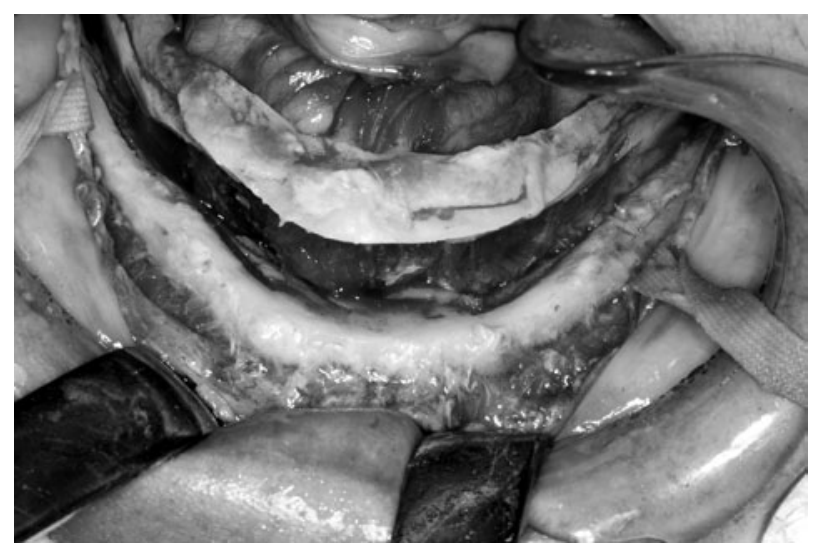

Figure 2. Visor shape of mandibular distal segment after the mobilizing the segments. from the anterior iliac crest were applied previous to the placement of osseointegrated dental implants. The patient was fitted with a Brånemark-type fixed prosthesis 6 months after the surgical procedure.

\section{CASE REPORT}

A 53-year-old female patient came to the Clinic of Oral and Maxillofacial Surgery of the Ribeirão Preto Dental School, University of São Paulo, Brazil, complaining of impairment of her masticatory function associated with the instability of the mandibular complete denture.

The clinical exam revealed edentulism in both arches, while the mandibular arch presented severe reabsorption resulting in denture instability and chronic trauma to the oral mucosa. The radiographic exam showed a mandibular atrophy class VI (Fig. 1), according Cawood and Howell (12), that made unpredictable any rehabilitation based on osseointegrated implants.

The treatment plan proposed consisted of 3 steps: 1) to apply the modified visor osteotomy technique together with autogenous bone graft harvested from the iliac crest; 2) the placement of at least 5 osseointegrated implants with a minimum length of $13 \mathrm{~mm}$; and 3) to construct a fixed Brånemark's protocol prosthesis.

The first surgical procedure was applied under general anesthesia at the Hospital of Clinics at the Medical School, University of São Paulo, Brazil. The technique performed (Figs. 2-5) followed that proposed by Härle (13) and modified by Peterson and Slade (14).

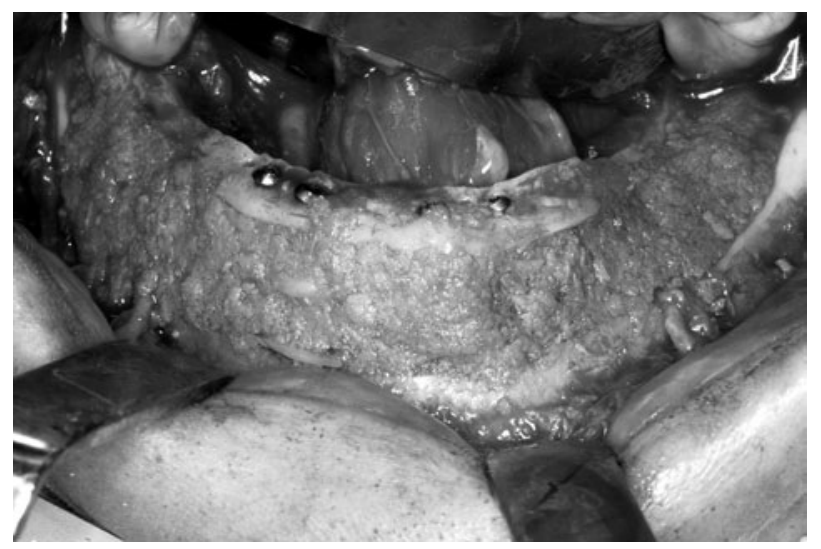

Figure 3. Autogenous corticocancellous bone grafts placed in an intepositional fashion, fixed with 2.0 titanium screws. Only particulated bone was placed in the posterior aspect of the mandible. 
After 6 months (Fig. 5) 6 osseointegrated implants with dimension of $3.75 \times 15 \mathrm{~mm}$ were implanted (Fig. 6) according to a previous prosthetic treatment plan. Four months later, these implants were exposed to the oral cavity using abutment healings preserving the keratinized gingiva, and 3 weeks after that the patient was referred to the prosthesist. Twelve months after the installation of the final Brånemark protocol prosthesis (Fig. 7), the evaluation of the osseointegrated implants revealed success according to the previously established criteria (15).
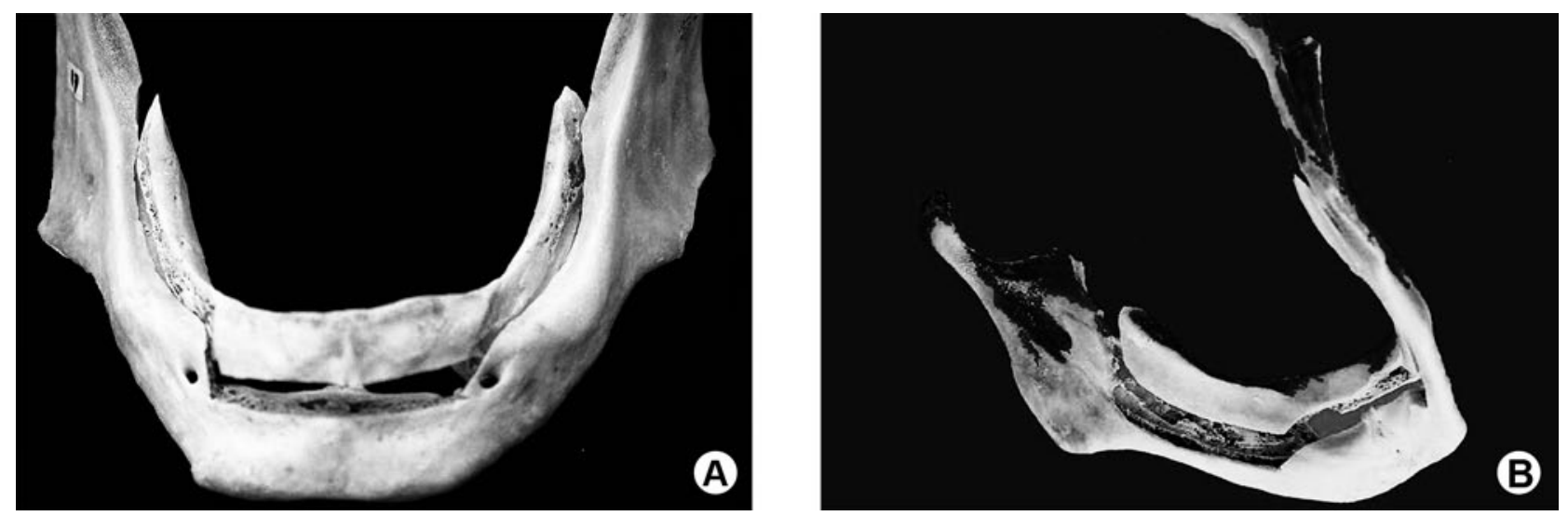

Figure 4. Different views of modified visor osteotomy in a dry mandible.

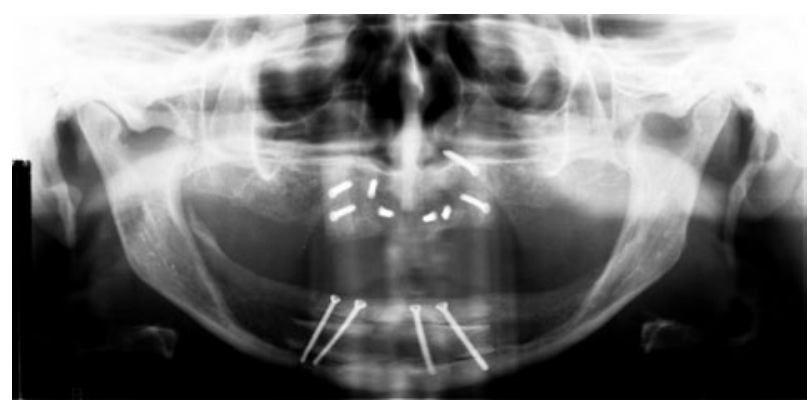

Figure 5. Uniform augmentation both in anterior and posterior region of the mandible, as demonstrated in a panoramic radiograph.

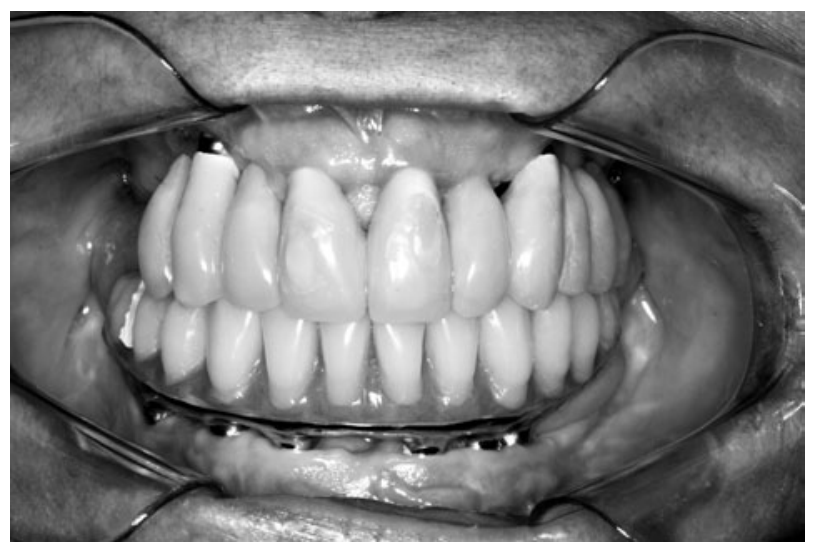

Figure 7. Good oral health after 12 months of follow up.

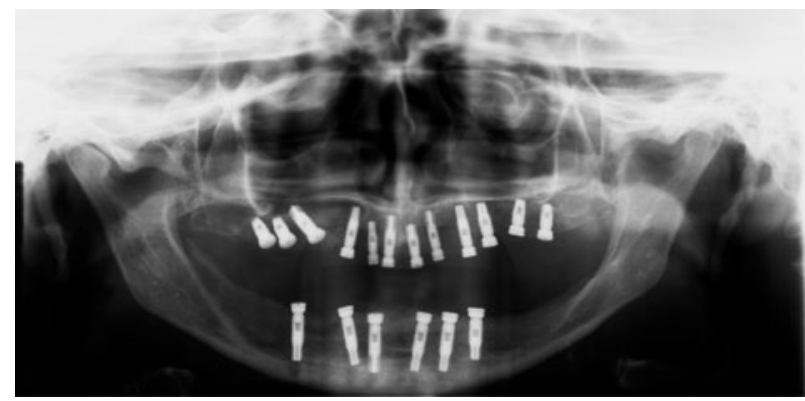

Figure 6. Placement of long implants for rehabilitation of the edentulous mandible.

\section{DISCUSSION}

Despite the advancements achieved by dentistry in the last three decades, the prosthetic rehabilitation of severely resorbed edentulous mandibles still remains a great challenge for the prosthesist and surgeon. An adequate handling of soft tissue usually improves the stability of a prosthetic denture in those cases in which the patient has an adequate residual bone volume. Nevertheless, when the patient has suffered severe bone loss (e.g., due to bone atrophy) it is necessary to associate hard tissue management. The bone graft is an valuable alternative and the advantages of this "gold 
standard" technique are: 1) improvement of the relationship between mandible and maxilla; 2) increase of the mandibular bone volume; 3 ) improvement of the shape of the residual alveolar ridge and; 4) improvement of function and esthetic of the prosthetic treatment (16).

The use of short implants (length up to $7 \mathrm{~mm}$ ) is an alternative to the preprosthetic reconstructive surgery. Some authors evaluated the use of these implants in severely resorbed edentulous mandible and found a similar rate of success to those implanted in mandibles with lesser rates of resorption $(1,5)$. Two disadvantages of this philosophy of treatment are: 1 . the unfavorable crown/implant ratio and; 2 . the higher risk of mandible fracture. The fracture of edentulous mandibles severely resorbed that have undergone the placement of osseointegrated implants is not uncommon $(2,3,7)$. The sites where the implants are fastened become weaker, predisposing them to fractures that occur more frequently during the osseointegration period $(3,7)$.

We believe that the prosthetic rehabilitation must aim not only for the replacement of the lost normally erupted teeth, but also a gain in the mandible bone mass, mainly in the body region where the bone atrophy is generally more intense. Now that life expectancy has increased significantly (16), these treatments involving the reinforcement of the mandible body are becoming more important.

Härle was the first author to report the use of the visor osteotomy technique in severely resorbed edentulous mandibles (13). The procedure consisted of splitting the mandible between the vestibular and lingual cortical, applying a mandibular body osteotomy from one side to the other. The lingual segment, containing the vascular pedicle, was positioned above as a helmet's visor and fixed with wires or screws allowing an increase of the mandibular height (16).

Peterson and Slade (14) proposed in 1977 some modifications: 1) to extend the osteotomy farther to the back, increasing the size of the lingual segment; 2) to add particulated autogenous bone graft in the posterior area increasing the bone volume; 3) to perform the vestibuloplasty simultaneously. The addition of autogenous bone graft allowed a more adequate shape to the posterior residual alveolar ridge and also increased the bone mass in this area where the bone atrophy is usually more intense. Despite these advantages, the use of this technique is not widely used because it is technically demanding.
Stoelinga et al. (17) reported their experience in the use of interpositional autogenous bone graft in severely resorbed edentulous mandible. Bell and Buckles (18) described similar techniques to the anterior region of the mandible, while DeKoomen et al. (19) suggested a more oblique osteotomy to the original technique proposed by Härle, in the anterior region of the mandible. The interpositional autogenous bone graft was also applied to gain mandibular height. Frost et al. (16) associated the bilateral lateralization of the inferior alveolar nerve (IAN) and the use of wafer-shaped bone graft that was stabilized in the anterior region with wires.

Peterson (20) suggested that the osteotomy between the mental foramens should be performed horizontally allowing the insertion of blocks of autogenous bone graft between the segments. According to the author, slight Class III arch discrepancies could be corrected by the backward movement of the superior segment. The author also proposed not performing the lateralization of the IAN, intending to get lesser rates of sensory deficit. However, the gain of bone height was drastically reduced. Furthermore, to the best of our knowledge there is no article in the scientific indexed literature evaluating the sensory deficit with and without the IAN handling.

Usually the molars are lost first than the other teeth in the mandible, exposing the mandibular body to bone atrophy for a longer time, resulting in lack of bone volume. Therefore, the gain in bone mass proposed in the modified visor osteotomy technique can help to prevent spontaneous fractures in severely resorbed edentulous mandible. By performing the lateralization of the IAN it is possible to extend the osteotomy in both directions, inferiorly to the mandibular base and posteriorly to the mandibular ramus, allowing more superior movement of the lingual segment and also a larger area to receive the autogenous bone graft. Nevertheless, this mandible reinforcement only occurs after the bone graft incorporation. Therefore, during the intraoperative and immediate postoperative periods the mandible is weaker and more predisposed to fractures than before the surgery. The patients must be advised about this potential complication and oriented how to prevent it. The exposition to potential etiologic factors for mandible fracture (e.g. contact sports and interpersonal altercation) must be avoided and the consistency of the food must be soft. Furthermore, in the first 2 months the patients should be monitored weekly in order to reiterate the advice and 
intercept and treat this complication as soon as possible.

Unfortunately, suture dehiscence with subsequent bone graft exposure and/or loss can happen. The patient of this case exhibited a $10 \mathrm{~mm}$ suture dehiscence 7 days after the surgery and two additional procedures (debridement and suture) were done under local anesthesia. Bone graft exposure up to $5 \mathrm{~mm}$ can be treated with just local irrigation with sterilized saline solution (20). Nevertheless, for exposure higher than $5 \mathrm{~mm}$, it is necessary to apply debridement and suture as soon as possible.

Peterson (20) stated that the most common postoperative complication is the occurrence of sensatory deficit in the area of the mental nerves. Some patients may have physical and emotional problems dealing with it $(16,20)$, and should be warned about this side effect during the discussion of the treatment plan. In fact, the intra or postoperative occurrence of mandible fracture is the most serious complication mentioned in the scientific indexed literature. While the fracture of the lingual segment has minor implications, the fracture of the vestibular segment containing the mandibular base can be difficult to treat. Therefore, this technique of mandibular reconstruction should be applied in mandibles with at least $8 \mathrm{~mm}$ of height (20).

The modified visor osteotomy technique, applied together with autogenous bone graft harvested from the iliac crest, offers predictable results for reconstruction of the severely resorbed edentulous mandible and posterior rehabilitation with osseointegrated implants.

\section{RESUMO}

A reabilitação protética de mandíbulas edêntulas muitas vezes torna-se insatisfatória em função da falta de tecido de suporte para reabilitação com implantes osseointegrágeis ou mesmo próteses totais convencionais. A falta de estabilidade protética ocasiona perda de qualidade de vida, pois geralmente resulta em limitação funcional e transtornos sociais. Este artigo descreve um caso clínico de uma paciente de 53 anos que procurou atendimento em nosso serviço queixando-se de dificuldade em mastigação e instabilidade da prótese total inferior, e apresentando atrofia severa de mandíbula. A reabilitação mandibular foi realizada com prótese fixa do tipo protocolo Brånemark, após cirurgia pré-protética reconstrutora com a utilização da osteotomia em "viseira modificada" e enxerto ósseo autógeno. A técnica proposta ofereceu resultados previsíveis para a reconstrução de mandíbulas severamente reabsorvidas para posterior reabilitação com implantes osseointegráveis.

\section{REFERENCES}

1. Stellingsma C, Vissink A, Meijer HJ, Kuiper C, Raghoebar GM.
Implantology and the severely resorbed edentulous mandible. Crit Rev Oral Biol Med 2004;15:240-248.

2. Kan JY, Lozada JL, Boyne PJ, Goodacre CJ, Rungcharassaeng K. Mandibular fracture after endosseous implant placement in conjunction with inferior alveolar nerve transposition: a patient treatment report. Int J Oral Maxillofac Implants 1997;12:655-659.

3. Stratigos GT, Cassara A, Birnbaum M. Reverse visor osteotomy for augmentation of the atrophic edentulous mandible. J Oral Maxillofac Surg 1982;40:231-233.

4. Brazilian Institute of Geography and Statistics (IBGE). Available from: http://www.ibge.gov.br (Latest access December 11, 2009).

5. Kao SY, Yeung TC, Hung KF, Chou IC, Wu CH, Chang RC. Transpositioned flap vestibuloplasty combined with implant surgery in the severely resorbed atrophic edentulous ridge. J Oral Implantol 2002;28:194-199.

6. Verhoeven JW, Cune MS, Terlou M, Zoon MA, de Putter C. The combined use of endosteal implants and iliac crest onlay grafts in the severely atrophic mandible: a longitudinal study. Int J Oral Maxillofac Surg 1997;26:351-357.

7. Worthington P, Rubenstein JE. Problems associated with the atrophic mandible. Dent Clin North Am 1998;42:129-160.

8. Bianchi A, Felice P, Lizio G, Marchetti C. Alveolar distraction osteogenesis versus inlay bone grafting in posterior mandibular atrophy: a prospective study. Oral Surg Oral Med Oral Pathol Oral Radiol Endod 2008;105:282-292.

9. Güven O. Rehabilitation of severely atrophied mandible using free iliac crest bone grafts and dental implants: report of two cases. J Oral Implantol 2007;33:122-126.

10. Marchetti C, Trasarti S, Corinaldesi G, Felice P. Interpositional bone grafts in the posterior mandibular region: a report on six patients. Int J Periodontics Restorative Dent 2007;27:547-555.

11. Moses O, Nemcovsky CE, Langer Y, Tal H. Severely resorbed mandible treated with iliac crest autogenous bone graft and dental implants: 17-year follow-up. Int J Oral Maxillofac Implants 2007;22:1017-1021.

12. Cawood JI, Howell RA. A classification of the edentulous jaws. Int J Oral Maxillofac Surg 1988;17:232-236.

13. Härle F. Visor osteotomy to increase the absolute height of the atrophied mandible: a preliminary report. J Maxillofac Surg 1975;3:257-260.

14. Peterson LJ, Slade EW Jr. Mandibular ridge augmentation by a modified visor osteotomy: preliminary report. J Oral Surg 1977;25:999-1004.

15. Smith DE, Zarb GA. Criteria for success of osseointegrated endosseous implants. J Prosthet Dent 1989;62:567-572.

16. Frost DE, Gregg JM, Terry BC, Fonseca RJ. Mandibular interposicional and onlay bone grafting for treatment of mandibular bone deficiency in the edentulous patient. J Oral Maxillofac Surg 1982;40:353-360.

17. Stoelinga P, Tideman H, Beger J, DeKoomen H. Interpositional bone graft augmentation of the atrophic mandible: preliminary report. J Oral Maxillofac Surg 1978;36:30-32.

18. Bell WH, Buckles RL. Correction of the atrophic alveolar ridge by interpositional bone grafting: a progress report. J Oral Surg 1978;36:693-700.

19. DeKoomen J, Stoelinga P, Tideman H, Huybers T. Interpositional bone graft augmentation of the atrophic mandible (a progress report). J Maxillofac Surg 1979;7:129-135.

20. Peterson LJ. Augmentation of the mandibular residual ridge by a modified visor osteotomy. J Oral Maxillofac Surg 1983;41:332-338. 